\title{
A importância da identificação humana nos desastres de massa naturais, acidentais ou provocados: uma abordagem multidisciplinar
}

\section{The importance of human identification in natural, accidental or provoked disasters: a multidisciplinary approach}

\author{
Karina Silva Funabashi ${ }^{1}$, Ana Carolina Monteiro², Danilo Alves de Moraes², Murilo \\ Ramos Rocha², Patricia Cristina Fincatti Moreira ${ }^{2}$, Edna Sadayo Miazato Iwamura ${ }^{3}$
}

Funabashi KS, Monteiro AC, de Moraes DA, Rocha MR, Moreira PCF, Iwamura ESM. A importância da identificação humana nos desastres de massa naturais, acidentais ou provocados: uma abordagem multidisciplinar. Saúde, Ética \& Justiça. 2009;14(2):54-64.

Resumo: Desastres de massa sempre existiram e agora ocorrem com maior frequência pela ação do homem. Dessa forma, consideramos importante a inclusão desse tema, tanto pelo caráter multidisciplinar dos trabalhos que se seguem aos desastres, em que profissionais das áreas da saúde, justiça e defesa civil estão envolvidos, bem como por ser do interesse de toda a sociedade. O escopo deste artigo é apresentar alguns dos principais acidentes de massa ocorridos nos últimos anos descritos na literatura enfocando as questões que se colocam aos profissionais nessas situações, bem como os avanços científicos e sua importância na identificação humana. Apresentamos: a) as dificuldades encontradas na identificação das vítimas dos ataques terroristas de 11 de setembro de 2001 no World Trade Center; b) o uso das técnicas para identificação de vítimas de guerras, genocídios; c) o uso das técnicas para identificação de vítimas de catástrofes naturais como o do Tsunami no Sul da Ásia em 26 de dezembro de 2004; d) a identificação do respomsável por um atentado em Jakarta em 2004: e) a Internet como ferramenta na vigilância da saúde na Geórgia em vítimas do furacão Katrina, ocorrido em 29 de agosto de 2005 e suas consequências. Como consideração final, apresentamos algumas recomendações, descritas após experiências vivenciadas em eventos dessa natureza.

Descritores: Antropologia forense; Vítimas de desastres; Patologia legal/métodos.

\footnotetext{
1 Pós-graduanda (Mestrado) do curso de Pós-graduação em Patologia - Departamento de Patologia - Escola Paulista de Medicina/Universidade Federal de São Paulo - EPM/UNIFESP.

2 Graduandos do curso de Biomedicina da Escola Paulista de Medicina/Universidade Federal de São Paulo - EPM/ UNIFESP.

${ }^{3}$ Professor adjunto do Departamento de Patologia - Escola Paulista de Medicina/Universidade Federal de São Paulo - EPM/UNIFESP.

Endereço para correspondênCiA: Profa - Dra Edna S. Miazato Iwamura. Rua Botucatu, 740. Edifício Lemos Torres. CEP 04023-062. Vila Clementino, São Paulo, SP. E-mail: eiwamura@gmail.com
} 
Funabashi KS, et al. A importância da identificação humana nos desastres de massa naturais

INTRODUÇÃO

$\mathrm{D}$ esastre de massa é um evento inesperado que causa sérios danos e mortes a um grande número de pessoas. Esses eventos podem ser desastres naturais, como terremotos, tsunamis e tornados; desastres acidentais, por exemplo, quedas de aviões, colisões e descarrilamentos de trens e incêndios; ou atos terroristas, tais como bombardeios, ataques suicidas e uso de armas químicas e biológicas ${ }^{1}$.

Os desastres de massa sempre existiram e agora com maior frequência, pela ação do homem. Os relatos contam com milhares de vítimas desde 1900 a 2007. Terremotos, furacões, tsunamis, enchentes, e outros desastres naturais já fazem parte da história da humanidade há algum tempo².

Segue a seguir uma lista dos maiores desastres naturais registrados na História, incluindo o número de mortes contabilizadas.

Existem váriosfatorese circunstâncias específicos inter-relacionados envolvidos em cada desastre de massa que podem constituir-se em desafio para a identificação das vítimas, como: número de vítimas, mecanismo de destruição dos corpos, extensão da fragmentação dos corpos, taxa de degradação do DNA, facilidade de obtenção de amostras dos corpos ou tipo de amostra de DNA disponíveis'.

A identificação forense de vitimas de desastres de massa é essencial por razões não apenas humanitárias, mas também devido à necessidade de investigação civil e/ou criminal, e é essencialmente baseada em antropologia, odontologia e patologia forense utilizando análises de radiografias, de tomografias e de perfil genético do DNA ${ }^{3}$.

Em um primeiro momento as técnicas mais simples e de menor custo, como identificação por marcas de diferenciação e arcada dentária, devem ser utilizadas. Porém, em um desastre de massa, nem todas as amostras possibilitarão o uso das técnicas de identificação tradicionais devido ao alto nível de degradação das amostras.

A melhor fonte para obtenção de amostras de DNA não degradadas em desastres de massa são os ossos e dentes. Os procedimentos para extração de DNA de ambas amostras são bem estabelecidos, porém são laboriosos e demorados.

Os perfis de DNA post-mortem resgatados dos desastres de massa são comparados com perfis de DNA de referências, que podem ser amostras ante-mortem da vítima, como amostras biológicas (biópsia tecidual), ou objetos pessoais (roupa não lavada, escova de cabelo ou de dente), ou amostras de parentes da vítima, que permitem uma identificação indireta da vítima por análise de parentesco ${ }^{3}$.

A análise por DNA, por sua vez, é única na sua habilidade de fornecer informações de identidade de qualquer tipo de tecido, desde que a amostra possua uma quantidade suficiente de DNA. Esta condição é crucial em acidentes em que a fragmentação corpórea é severa ${ }^{4}$.

Atualmente, a tecnologia preferida para identificação por DNA em desastres de massa é a amplificação de marcadores obtidos por reação em cadeia da polimerase (PCR) de um número variável de loci de short tandem repeats (STR) autossômicos, devido à sua sensibilidade adequada e seu alto poder discriminativo. O contínuo desenvolvimento de marcadores multiplex (vários loci em uma única reação de PCR) de STR autossômicos, incluindo um aumento no número de loci de STR contribuiu para a padronização e validação internacional dessa tecnologia. Os kits atuais de marcadores por PCR para perfil de STR podem amplificar de 9 a 15 loci de STR além do locus da Amelogenina (para identificação do gênero) em uma única reação de PCR com alto poder discriminativo para avaliar combinações diretas entre as vítimas e seus objetos pessoais e para estudar potenciais relações de parentesco entre vítimas e seus parentes ascendentes e descendentes. Assim, STR é o padrão ouro para identificação de DNA em desastres de massa e apresenta resultados muito eficientes.

Porém, nos desastres de massa muitas amostras de DNA são degradadas e apresentam apenas moléculas muito pequenas, com menos de 150 pares de bases, o que torna a técnica de STR, utilizada na rotina (sensível de 150 a 400 pares de bases), ineficiente. Este foi um dos desafios encontrados no desastre do World Trade Center (WTC), o que resultou no desenvolvimento de novas técnicas de perfil por PCR pela amplificação de seqüências de DNA muito curtas. Um exemplo é o desenvolvimento de diferentes Mini-STR, baseado em seqüências (primers) redesenhados para obter seqüências 
Funabashi KS, et al. A importância da identificação humana nos desastres de massa naturais

Tabela 1. Lista dos maiores desastres naturais registrados na História

\begin{tabular}{|c|c|c|c|c|}
\hline Evento & Data & Tipo & Local & Mortes - Número \\
\hline & 1138 & Sismo & Aleppo, Síria & 230.000 \\
\hline \multirow[t]{3}{*}{ Peste negra } & $1330-1351$ & Epidemia & Ásia Central e Europa & $>175.000 .000$ \\
\hline & 1556 & Sismo & Shaanxi, China & 830.000 \\
\hline & 1737 & Sismo & Calcutá, Índia & 300.000 \\
\hline \multirow[t]{8}{*}{ Terremoto } & 1755 & Sismo/Incêndio/Tsunami & Lisboa, Portugal & 100.000 \\
\hline & 1815 & Erupção & Vulcão Tambora, Indonésia & 92.000 \\
\hline & 1883 & Erupção/Tsunami & Krakatoa, Indonésia & 36.000 \\
\hline & 1887 & Inundação & China & 1.000 .000 \\
\hline & 1902 & Erupção & Monte Pelée, Martinica & 35.000 a 40.000 \\
\hline & 1908 & Sismo/Enchentes & Messina, Itália & 70.000 a 100.000 \\
\hline & 1920 & Sismo & Gansu, China & 200.000 \\
\hline & 1923 & Sismo/Incêndio & Kanto, Japão & 143.000 \\
\hline \multirow[t]{3}{*}{ Inundação do Rio Amarelo } & 1931 & Inundação & China & 1.000 .000 a 2.000 .000 \\
\hline & 1948 & Sismo & Turcomenistão & 110.000 \\
\hline & 1962 & Erupção vulcânica & Huascarán, Peru & 3.000 \\
\hline \multirow[t]{3}{*}{ Ciclone de Bhola } & 1970 & Ciclone & Índia/Bangladesh & 300.000 a 500.000 \\
\hline & 1970 & Sismo & Peru & 66.000 \\
\hline & 1975 & Sismo & Haicheng, China & 10.000 \\
\hline \multirow[t]{10}{*}{ Sismo de Tangshan } & 1976 & Terremoto & Tangshan, China & 255.000 \\
\hline & 1985 & Sismo & Cidade do México, México & 9.500 \\
\hline & 1985 & Erupção vulcânica & Nevado del Ruiz, Colômbia & 23.000 \\
\hline & 1988 & Sismo & Armênia & 55.000 \\
\hline & 1991 & Ciclone & Bangladesh & 138.000 \\
\hline & 1995 & Sismo & Kobe, Japão & 4.571 \\
\hline & 1999 & Enchentes & Venezuela & 20.000 \\
\hline & 2001 & Sismo & Gujarat, Índia & 20.000 \\
\hline & 2001 & Sismo & Afeganistão & 2.500 \\
\hline & 2003 & Sismo & Bam, Irã & 31.000 \\
\hline Onda de calor na Europa & 2003 & Onda de calor & $\begin{array}{l}\text { Europa (sobretudo França, } \\
\text { Espanha e Itália) }\end{array}$ & 37.451 \\
\hline Terremoto do Índico & 2004 & Sismo/Tsunami & Sueste Asiático/África Oriental & 295.000 \\
\hline \multirow[t]{3}{*}{ Sismo do Paquistão } & 2005 & Sismo & Paquistão & 86.000 \\
\hline & 2006 & Sismo & Índia & 6.000 \\
\hline & 2006 & Tufão/inundações & China & 2.000 \\
\hline Ciclone Nargis & 2008 & Ciclone & Mianmar & 78.000 a 124.000 \\
\hline
\end{tabular}

Fonte: dados obtidos em "http://pt.wikipedia.org/wiki/Anexo:Lista_dos_maiores_desastres_naturais", acesso em 27/11/2009.

(amplicons) de no máximo 260 pares de base, o que aumentou eficientemente a taxa de sucesso da identificação por DNA no desastre do WTC em que os STR convencionais falharam ${ }^{5}$.

Outra técnica que obtém amplicons muito mais curtos (média de 69 pares de bases) do que os mini-STR é a do single nucleotide polymorphism
(SNP) autossômicos. SNPs são substituições inserções ou deleções de bases que ocorrem em posições únicas no genoma nuclear humano. Existe aproximadamente 1 SNP para cada 1000 pares de bases do DNA humano, ou seja, aproximadamente $85 \%$ das variações do genoma são baseadas em SNPs, o que significa que existe uma abundância 
Funabashi KS, et al. A importância da identificação humana nos desastres de massa naturais

de SNPs para identificação humana. Porém essa ténica também possui desvantagens, pois como a maioria dos SNPs são bi-alélicos eles são menos informativos para testes de identidade quando comparados com loci de STR. Além disso, um grande número de loci de SNPs são necessários para fornecer poder discriminatório estatístico suficiente para uma identificação positiva de vitima ${ }^{5}$.

Quando a quantidade de DNA extraída é muito baixa ou quando as amostras estão muito degradadas outra técnica que é muito útil é a amplificação e sequenciamento de sequências hipervariáveis 1 e 2 (HV1 e HV2) do DNA mitocondrial. O número de cópias de moléculas de mtDNA em uma célula é muito grande, cerca de 1000 cópias, enquanto existem apenas duas cópias de cada cromossomo no núcleo, o que torna o uso dessa técnica possível. Além disso, a forma circular do mtDNA o protege da degradação. De fato, em mais de 95\% das amostras ósseas em casos de pessoas desaparecidas, o sucesso na obtenção do perfil por mtDNA é alcançado. No entanto, muitas vezes o mtDNA sozinho não alcança a magnitude de certeza necessária para uma identificação positiva de um indivíduo, uma vez que apenas parentes da linhagem materna podem servir como referência de mtDNA. Outra desvantagem é que haplótipos comuns de mtDNA são encontrados em várias populações, associações casuais baseadas em mtDNA podem ocorrer, e esse evento aumenta conforme o número de vítimas aumenta ${ }^{5}$.

Assim, não existem técnicas sem desvantagens. O interessante é usar uma combinação dessas tecnologias, analisando em cada situação quais são as mais adequadas.

Mesmo com o desenvolvimento de todas essas técnicas, em desastres de massa a identificação de vítimas pode ser um processo complexo. Geralmente, um grande número de amostras é coletado e analisado, e uma variedade de estudos são realizados (desde estudo da arcada dentária até perfil de DNA). Eenquanto a geração de informaçãoé enfatizada o gerenciamento da mesma comumente não recebe a atenção adequada 5 . Assim, gerenciar a grande quantidade de análises e dados gerados em desastres de massa, mantendo a qualidade é um desafio substancial. Torna-se necessário o desenvolvimento de softwares específicos que organizem, armazenem e comparem informações, além de calcularem a razão de verosimilhança (likelihood ratio) para avaliar a significância de cada comparação positiva e eficiente das informações biológicas de um conjunto de informações genéticas ${ }^{4}$.

\section{OS ATAQUES TERRORISTAS DE 11 DE SETEMBRO}

Os ataques às torres do World Trade Center em Nova lorque em 11 de setembro de 2001 representaram a maior fatalidade causada por um único atentado terrorista na história dos Estados Unidos ${ }^{6}$. Toda a estrutura forense para "desastres em massa" estava preparada para eventos na escala de 500 vítimas. Mas as quase 3 mil vítimas desse atentado forçaram uma adaptação, melhoramento e capacitação dos serviços de socorro e em especial dos serviços de identificação de cadáveres ${ }^{7}$.

A identificação de cerca de 2700 vítimas, representadas por aproximadamente 15000 peças, teve que se basear quase que exclusivamente no DNA, para não se sujeitar a identificações errôneas, como aconteceu no início da investigação ${ }^{8}$. Devido às circunstâncias do desastre, as peças corporais estavam muito fragmentadas (chegando a serem encontrados 200 fragmentos ósseos de um mesmo indivíduo), expostas a altíssimas temperaturas dentro da estrutura das torres, e também à umidade. As análises de DNA iniciais foram feitas a partir de amostras de tecido mole encontradas. Contudo, percebeu-se que estas amostras eram mistas, apresentando diferentes perfis genéticos, o que mostrava que aquele tecido aparentemente único seria a junção de fragmentos corporais de diferentes indivíduos ${ }^{9}$. A extração de DNA a partir de ossos, mostrou melhores resultados. Esses resultados foram obtidos devido a melhorias metodológicas na técnica de extração, na forma de limpeza, a preparação e separação do material, visando uma maior eficiência e rapidez na identificação6 ${ }^{\text {. }}$

Entretanto, o estado precário de algumas amostras obrigou a realização de testes de miniSTRs (como já citado anteriormente), mtDNA e até mesmo SNPs. As análises utilizando essas diferentes metodologias foram realizadas até se completar um perfil genético que permitisse uma comparação com amostras de referência.

Assim como a técnica de extração em si, avanços 
na análise dos dados, por meio da estatística foram de extrema importância na identificação das vítimas, por meio da definição consciente e clara de alguns valores desejáveis para os "likelihood ratios". Assim como será comentado nas recomendações mais à frente, sabe-se que a definição do limites para os likelihood ratios é de grande importância na composição dos perfis e comparação de dados.

A área forense e seus profissionais aprenderam muito com os atentados terroristas de 11 de setembro, e são essas melhorias que têm guiado o trabalho em novos casos e dado rumo para o avanço dessa ciência ${ }^{6}$.

USO DAS TÉCNICAS PARA IDENTIFICAÇÃO DE VÍTIMAS DE GUERRAS E GENOCÍDIOS

Em casos de guerra civil em que governos repressores ou em crise atuam contra segmentos da população, geralmente tem-se um grande número de desaparecidos, além da posterior descoberta de covas coletivas. $\mathrm{Na}$ antiga lugoslávia, região marcada pela desintegração de Estados-nação e pelos conflitos de motivação política e étnica, o contingente de pessoas desaparecidas é bastante elevado, o que é reflexo da verdadeira guerra civil que se abateu por todo o leste europeu após a desintegração da antiga URSS e do bloco socialista. Assim, o uso de técnicas de identificação de pessoas desaparecidas e de vítimas de guerra por análise de STRs pode constituir uma ferramenta importante para restituir às famílias os restos mortais destes indivíduos.

A International Commission on Missing Persons (ICMP) é um exemplo de organização que reconhece o valor das técnicas envolvendo STRs para identificar indivíduos desaparecidos, uma vez que está empreendendo um grande esforço para congregar laboratórios, aliados políticos e centros de apoio a familiares de desaparecidos para conseguir identificar o elevado contingente de restos mortais encontrados em covas coletivas na antiga lugoslávia. Este esforço - que tem apoio financeiro tanto do poder público quanto da iniciativa privada - passa também pelo incentivo a avanços tecnológicos nos campos de armazenamento e análise de dados ${ }^{10}$.

Nestes casos, a identificação se dá pela comparação do perfil genético do desaparecido com um grande banco de dados que contém os perfis de membros das famílias que reclamam algum parente. Assim, dado o tamanho do universo para comparação, a análise deve usar o maior número de STRs possível, sendo que a utilização de 15 deles garante resultados de alto poder discriminatório na maioria dos casos - mas não em todos. As amostras usadas geralmente são de osso pulverizado - no caso dos cadáveres dos indivíduos não identificados - e de sangue - no caso dos familiares interessados na comparação. Os kits AmpFLSTR Profiler, Profiler Plus e Identifiler são os mais utilizados, e no caso de aparente endocruzamento entre indivíduos encontrado em 295 pessoas que não apresentavam parentesco -, é feita a análise de mini-haplótipos, na qual todas as possíveis combinações de três loci dos STRs analisados pelo kit AmpFLSTR Profiler Plus são verificadas.

Mesmo usando um número de STRs maior do que o usualmente adotado para a análise, resultados inconclusivos ainda são obtidos. Na comparação da análise dos restos mortais de 98 indivíduos exumados com um banco de dados de 3000 genótipos de parentes de pessoas desaparecidas, foram encontrados 20 casos em que houve igualdade de 14 loci e 4 casos de igualdade de 15 loci entre pessoas que não tinham qualquer parentesco. Esses "falsos positivos" podem ser devidos ao endocruzamento de famílias da região, o que foi reforçado pela análise de mini-haplótipos, que em alguns casos estavam presentes em $90 \%$ das amostras. Tudo isso serve para mostrar que a identificação de indivíduos por análise comparativa de STRs é uma ferramenta valiosíssima em casos de um grande contingente de desaparecidos, mas que o poder conclusivo da técnica aumenta quando se tem acesso a amostras de vários parentes da família interessada, bem como a dados antropológicos e também investigativos, tratando das circunstâncias do desaparecimento do indivíduo ${ }^{11}$.

USO DAS TÉCNICAS PARA A IDENTIFICAÇÃo DE VÍTIMAS DE CATÁSTROFES NATURAIS

No que se refere às catástrofes naturais, a má gestão dos corpos tem conseqüências para o bemestar psicológico dos sobreviventes. Entretanto, não existe um guia técnico para a gestão de mortes em massa após grandes catástrofes naturais. Métodos existentes aplicados em casos de acidentes de 
Funabashi KS, et al. A importância da identificação humana nos desastres de massa naturais

trânsito e atos terroristas não são diretamente transferíveis para as catástrofes naturais. Além disso, não há muita informação disponível sobre esse tema ${ }^{12}$.

No mundo inteiro, ocorrem pelo menos seis desastres naturais a cada ano que matam mais de 500 pessoas. Esses desastres normalmente levam a uma reação comum, que é o medo de uma possível epidemia causada pelos corpos das vítimas. Esse medo tem sido uma justificativa freqüente para o sepultamento rápido dos restos mortais humanos em covas coletivas sem identificação. Isso traz conseqüências como sofrimento psicológico para os sobreviventes e problemas legais envolvendo herança, indenização e seguro ${ }^{12}$.

Para exemplificar, peguemos como base 0 Tsunami no Sul da Ásia em 26 de dezembro de 2004. Este foi um dos maiores desastres naturais dos últimos tempos, com uma estimativa de 220 mil mortos, afetando mais de 10 países.

Para a identificação dos corpos, quando os mesmos se encontravam conservados, foram utilizados dados dentários e impressões digitais, além da identificação visual direta por parentes. A presença de objetos pessoais, jóias, documentos de identificação e celulares também auxiliou a identificação de alguns cadáveres. A fotografia também foi muito utilizada, devido à dificuldade no armazenamento desses corpos ${ }^{13}$.

Já a análise do DNA, para a identificação individual, fez-se necessária devido ao grande número de cadáveres que sofreram rápida decomposição. Isso tornou não apenas o processo de coleta do material difícil, mas também levantou dúvidas quanto ao sucesso da identificação pelo DNA. Foram coletadas amostras de ossos e dentes para a análise do DNA. Devido à pequena quantidade e à degradação do DNA nuclear, nas amostras de dentes foram analisadas as seqüências de DNA mitocondrial. Já nas amostras de ossos foram possíveis análises dos STRs de DNA autossômicos ${ }^{14}$.

Esse perfil do DNA foi utilizado em uma comparação direta, da mesma maneira que os dados dentários e as impressões digitais, no qual o perfil do DNA ante-mortem é comparado com o perfil do DNA post-mortem. Esse material antemortem pode ser obtido facilmente de objetos pessoais do indivíduo, como por exemplo, escova de dente, pente e barbeador. Há ainda um método alternativo para a identificação através do perfil do DNA, caso o método direto não consiga gerar um perfil completo do DNA. Trata-se de uma comparação indireta, utilizando o perfil do DNA dos parentes. Para isso, foi necessária a coleta de amostras de sangue dos parentes mais próximos da vítima ${ }^{15}$.

Entretanto, foi nítida a diferença no gerenciamento das vítimas em cada país, como por exemplo, quando comparamos a Tailândia, que recebeu auxilio de diversos países, sendo considerada a maior investigação forense internacional seguida de um desastre natural, com outros, nos quais autoridades locais foram deixadas para lidar da melhor maneira possível. Essas diferenças são vistas nos métodos usados por cada país para recuperar e armazenar os corpos, identificar as vítimas e eliminar os restos mortais humanos ${ }^{12}$.

Dessa forma, pode-se observar que um bom planejamento, um financiamento adequado e a cooperação internacional são essenciais para montar uma resposta eficaz a qualquer desastre de massa do futuro ${ }^{13}$.

O OUTRO LADO: IDENTIFICAÇÃO DE RESPONSÁVEIS POR DESASTRES DE MASSA

A análise de DNA também é útil não só para a identificação de vítimas de desastres de massa - uso mais freqüentemente visto até aqui. É possível também identificar responsáveis por estes desastres. Por exemplo, casos de atentados terroristas em que homens-bomba (indivíduos de crença fundamentalista que se dispõem a carregar explosivos junto ao corpo e detoná-los em locais públicos) explodem com a bomba virtualmente sem deixar vestígios.

No caso do atentado à embaixada australiana em Jacarta, na Indonésia, ocorrido em 9 de Setembro de 2004, o criminoso estava dentro de um carro em que havia uma bomba, detonando-a. Como resultado, o corpo foi reduzido a pequenos fragmentos de tecidos e orgãos carbonizados, inviabilizando qualquer possibilidade de identificação visual. Foram recuperadas 121 amostras, com grande probabilidade de pertencer 
ao corpo do criminoso. A trajetória dos fragmentos da bomba foi reconstituída, direcionando a coleta de fragmentos de tecido carbonizado do criminoso. A análise de DNA mitocondrial foi realizada, confirmando a fonte comum de 17 fragmentos e estabelecendo o perfil da região hipervariável 1 (HV1) do criminoso. Além disso, esse perfil revelouse igual ao da mãe de um dos quatro suspeitos e o parentesco foi confirmado pela análise dos STRs - obtidos em sua totalidade de apenas 3 das 17 amostras de tecido usadas ${ }^{15}$.

\section{A INTERNET COMO FERRAMENTA NA VIGILÂNCIA DA SAÚDE}

A Internet revolucionou o modo de funcionamento das instituições do governo. A forma como a vigilância de saúde é conduzida não ficou de fora desta revolução. O Estado da Georgia (EUA) tem usado essa ferramenta para notificação de doenças, problemas na energia e detecção precoce de eventos. Essa mesma ferramenta foi utilizada na saúde pública, em resposta aos 125 mil evacuados do Furacão Katrina que vieram à Georgia.

Em 29 de agosto de 2005, o Furacão Katrina atingiu a Costa do Golfo. A Georgia recebeu o segundo maior número de evacuados do Furacão Katrina. Dentro de dias, foram montados abrigos para os evacuados; entretanto, estes abrigos tornaram-se lotados, o que aumenta o risco para doenças transmissíveis. Além disso, muitos dos evacuados deixaram para trás suas medicações, o que aumentou o risco de doenças crônicas.

Os residentes e pacientes dos abrigos que visitaram os departamentos de emergência reportaram principalmente doenças crônicas. Entre as 33 mortes de evacuados, apenas duas foram de doenças infecciosas e uma relacionada indiretamente com o furacão.

Dessa forma, a Internet foi essencial para coletar dados de saúde de vários locais e de muitas pessoas diferentes durante a resposta da saúde pública da Georgia ao Furacão Katrina ${ }^{16}$.

\section{ReCOMENDAÇõES}

A imprevisibilidade de um desastre em massa e sua proporção drástica sempre farão parte da realidade daqueles envolvidos em um evento desse tipo. Mas diversas agências governamentais e não-governamentais criaram recomendações, guias ou manuais para que haja uma ordem no meio de tanto caos. A identificação de cadáveres em acidentes de massa, apesar de não constituir a intuitiva resposta primária, não deve ser deixada de lado, mas, sim, estar integrada a outros esforços para uma melhor eficiência do atendimento a essas situações.

Cadaacidenteemmassatema sua peculiaridade. Por esta razão, a capacitação de profissionais, treinamentos e simulações periódicas, assim como um plano de mobilização e resposta a um desastre são de extrema importância. E integrada a estes planos deve estar a identificação de vítimas de desastres (IVD). Os aspectos multidisciplinares da identificação de vítimas e a abordagem que deve ser feita a esse assunto são extensamente enunciados e discutidos no "Interpol Guide to Disaster Victim Identification"17, no "The Pan American Health Organization disaster manual"18, em um artigo sobre fatalidades em massa publicado pelo Instituto Nacional de Justiça norteamericano ${ }^{19}$ e em um manual de campo para lidar com cadáveres após desastres ${ }^{20}$. Abordaremos algumas das recomendações mais pertinentes sob o ponto de vista da genética forense e daqueles que a praticam direta ou indiretamente (recomendações feitas por Prinz et al. ${ }^{21,22}$ ).

Recomendação 1: Todo laboratório de DNA forense deve manter contato com a autoridade relevante a respostas de emergência, para estabelecer um envolvimento nos planos de preparação para o caso de uma fatalidade em massa. Devem ser tomadas o quanto antes, decisões no que diz respeito a: coleta de amostras, escopo e objetivos finais dos esforços, pois estes afetam as famílias da vítimas e o fluxo de trabalho. De acordo com as recomendações da Interpol ${ }^{16}$, cada país deveria ter uma equipe nacional de identificação de vítimas para administrar os esforços nesse sentido, em caso de desastre. Já os laboratórios forenses, quando não forem diretamente subordinados a essa equipe nacional, deveriam manter um diálogo constante, formando uma rede de laboratórios capacitados e capazes de trabalhar em conjunto em caso de um desastre. É também de suma importância que exista um nível adequado de competência, provado 
Funabashi KS, et al. A importância da identificação humana nos desastres de massa naturais

através de testes de proficiência e acreditações. O laboratório de DNA não deve ser um simples local para testes. Ele deve fazer parte na montagem do plano de ação, assim como deve ser consultado com relação a coleta de materiais, treinamento de pessoal e assuntos a serem tratados com os familiares das vítimas.

Recomendação 2: O plano interno de resposta de um laboratório deve relacionar capacidade de processamento, rastreabilidade das amostras e conter os nomes dos responsáveis pelas diferentes tarefas que forem atribuídas no plano. A despeito do plano global de resposta a um desastre, cada laboratório de identificação por meio de DNA, deve ter seu plano interno. Esse plano deve focar na real capacidade de processamento do laboratório, dadas as limitações de capacidade de rastreabilidade, processamento e armazenamento; assim como questões metodológicas e de treinamento de pessoal. Deverá estar sempre claro, também, quem são os responsáveis por cada setor e suas tarefas em caso de desastre.

Recomendação 3: Diversos tipos de amostra devem ser coletados o quanto antes no processo de investigação para os testes de DNA, desde que seja mantida a rastreabilidade. Amostras devem ser coletadas de cada corpo ou parte reconhecível mesmo que a identidade já tenha sido estabelecida. Deve estar garantido também o devido acondicionamento desses materiais.

Recomendação 4: Múltiplas referências diretas e amostras de parentes de cada pessoa desaparecida devem ser coletadas. Cientistas com conhecimento em genética devem estar disponíveis para treinamento ou para aconselhamento com relação as famílias das vítimas.

Recomendação 5: Testes de DNA para identificação de vítimas de desastres devem ser realizados somente por laboratórios com capacidade e experiência demonstrada no processamento daquele tipo específico de amostra.

Recomendação 6: O conjunto de loci a ser analisado tem que ser decidido de acordo com a comunidade científica dos países envolvidos no desastre, assim que possível. Quanto maior o número de loci melhor, mas é preconizado um número mínimo de 12 loci independentes.

Recomendação 7: Todos os resultados de compatibilidade alélica e de perfis genéticos devem ser revisados exaustivamente. Pois perfis de DNA compostos podem ser gerados a partir do mesmo espécime. Tudo levando em consideração a logística e circunstância do desastre.

Recomendação 8: Caso a tipagem padrão por STRs autossomais seja incapaz de prover dados suficientes, sistemas de tipagem por mtDNA, STRs do cromossomo Y ou SNPs devem ser utilizados.

Recomendação 9: Para todas as comparações de dados é recomendado um banco de dados centralizado, o qual, de preferência, será eletrônico para evitar erros de transcrição na submissão de dados ao sistema.

Recomendação 10: Especialmente quando há múltiplos membros de uma família como vítimas, a identificação deve se basear em análises antropológicas, de dados circunstanciais ou múltiplas referências de DNA.

Recomendação 11: É de extrema importância no trabalho de identificação, a estatística, que é primariamente composta pelos "likelihood ratios". Essas razões permitem comparar os resultados de DNA e devem ser definidas de modo que o DNA seria suficiente para identificar a origem da amostra sem a necessidade de dados complementares (o que não implica que eles não devam ser analisados).

Recomendação 12: O plano de preparo do laboratório deve incluir políticas de notificação das famílias, acondicionamento de matérias por longos prazos e arquivamento de dados.

No Brasil, já tivemos alguns eventos recentes, como o acidente aéreo dentro da Cidade de São Paulo, envolvendo um avião da TAM em 1996, em que 99 pessoas a bordo e uma em terra foram vítimas fatais. Em 2006, ocorreu um acidente envolvendo um avião da Gol em plena selva Amazônica ${ }^{23}$ e, em 2007, um vôo da TAM 
Funabashi KS, et al. A importância da identificação humana nos desastres de massa naturais

no aeroporto de Congonhas derrapou durante o procedimento de pouso com a morte de todos os passageiros carbonizados.

Os relatos, as experiências vivenciadas e descritas demonstram que tivemos avanços na ciência, por outro lado, não existem planos de emergência para desastres de massa. Infelizmente, não temos como impedir outros eventos de ocorrer, no entanto, é necessário que se amplie a discussão a respeito das possibilidades de prevenção, de atuação e de atendimento à população nas situações relacionadas a desastres, incluindo desde profissionais da saúde e de gestão pública a setores privados e da sociedade civil. Podemos refletir, analisar e realizar medidas para prevenir, sempre. E, nisso, o trabalho de identificação, sem dúvida, desempenha um importante papel.

Funabashi KS, Monteiro AC, de Moraes DA, Rocha MR, Moreira PCF, Iwamura ESM. The importance of human identification in natural, accidental or provoked disasters: a multidisciplinary approach. Saúde, Ética \& Justiça. 2009;14(2):54-64.

ABSTRACT: Mass Disasters have always occurred and now with more frequency by the action of man. Thus, we consider important the inclusion of this topic, both by the multidisciplinary aspect of the work that follows the disasters, in which professionals from fields of health, justice and civil defense are involved, as well as to be of interest of the whole society. The scope of this paper is to present some of the main mass disasters in recent years published in the literature focusing on the issues in which professionals in these situations are involved, as well as the scientific advances and their significance for human identification. We present: a) the difficulties found in identifying victims of the terrorist attacks of September 11, 2001 at the World Trade Center; b) the use of techniques for identifying victims of wars, genocides; $c$ ) the use of techniques for identifying victims of natural disasters, as the tsunami in South Asia on December 26, 2004; d) the identification of the responsible of a mass disaster, in a bombing in Jakarta in 2004 and e) the Internet as a tool for monitoring the health in Georgia in Victims of Hurricane Katrina, occurred on August 29, 2005, and the event consequences. As the final consideration we present some recommendations, described after experiences in occurred events.

KEY WORDS: Forensic anthropology; Disaster victims; Disasters; Disasters pathology/trends.

REFERÊNCIAS

1. Alonso A, Martin P, Albarran C, Garcia $P$, Fernandez de Simon L, Jesus Iturralde $M$, et al. Challenges of DNA profiling in mass disaster investigations. Croat Med J. 2005;46(4):540-8.

2. Desastres naturais [Citado em 11 nov. 2007]. Disponível em http://veja.abril.com.br/ especiais_online/desastres_naturais/

3. De Valck E. Major incident response: collecting ante-mortem data. Forensic Sci Int. 2006;159(Suppl 1):S15-9.

4. Leclair B. Large-scale comparative genotyping and kinship analysis: evolution in its use for human identification in mass fatality incidents and missing persons databasing. Int Congress Series. 2004;1261:42-4.

5. Budowle B, Bieber FR, Eisenberg AJ. Forensic aspects of mass disasters: strategic 
Funabashi KS, et al. A importância da identificação humana nos desastres de massa naturais

considerations for DNA-based human identification. Leg Med (Tokyo). 2005;7(4):23043.

6. Holland MM, Cave CA, Holland CA, Bille TW. Development of a quality, high throughput DNA analysis procedure for skeletal samples to assist with the identification of victims from the World Trade Center attacks. Croat Med J. 2003;44(3):264-72.

7. Biesecker LG, Bailey-Wilson JE, Ballantyne $\mathrm{J}$, Baum H, Bieber FR, Brenner C, et al. Epidemiology. DNA identifications after the 9/11 World Trade Center attack A. Science. 2005;310(5751):1122-3.

8. Brenner $\mathrm{CH}$, Weir BS. Issues and strategies in the DNA identification of World Trade Center victims. Theor Popul Biol. 2003;63(3):173-8.

9. Budimlija ZM, Prinz MK, Zelson-Mundorff A, Wiersema J, Bartelink E, MacKinnon G, et al. World Trade Center human identification project: experiences with individual body identification cases. Croat Med J. 2003; 44(3):259-63.

10. Huffine E, Crews J, Kennedy B, Bomberger K, Zinbo A. Mass identification of persons missing from the break-up of the former Yugoslavia: structure, function, and role of the International Commission on Missing Persons. Croat Med J. 2001;42(3):271-5.

11. Birus I, Marcikic M, Lauc D, Dzijan S, Lauc G. How high should paternity index be for reliable identification of war victims by DNA typing? Croat Med J. 2003;44(3):322-6.

12. Morgan OW, Sribanditmongkol P, Perera C, Sulasmi Y, Van Alphen D, Sondorp E. Mass fatality management following the South Asian tsunami disaster: case studies in Thailand, Indonesia, and Sri Lanka. PLoS Med. 2006;3(6):e195.

13. Lau G, Tan WF, Tan PH. After the Indian Ocean tsunami: Singapore's contribution to the international disaster victim identification effort in Thailand. Ann Acad Med Singapore. 2005;34(5):341-51

14. Deng YJ, Li YZ, Yu XG, Li L, Wu DY, Zhou
$J$, et al. Preliminary DNA identification for the Tsunami victims in Thailand. Genomics Proteomics Bioinformatics. 2005;3(3):143-57.

15. Putut T, Widodo, Suryadi A, Yuliana S, Lie A, Dodi Safari, Agung Widjajanto, D. Aji Kadarmo, Soegeng Hidayat, Sangkot Marzuki. DNA analysis in perpetrator identification of terrorism-related disaster: suicide bombing of the Australian Embassy in Jakarta 2004 Herawati Sudoyo. Forensic Sci Int Genet. 2008;2:231-7.

16. Susan T. Cookson, MD, MPH, Karl Soetebier, MAPW, Erin L. Murray, MSPH, Geroncio C. Fajardo, MD, MBA, MS, Randy Hanzlick, MD, Alex Cowell, Cherie Drenzek, DVM, MS. Internet-Based Morbidity and Mortality Surveillance Among Hurricane Katrina Evacuees in Georgia. Centers for Disease Control and Prevention. Available from: http:// www.cdc.gov/pcd/issues/2008/oct/07_0239. htm

17. International Criminal Police Organization, Interpol Disaster Victim Identification Guide, 2002-2005. Avaliable from: http://www. interpol.int//Public/DisasterVictim/ default.asp

18. Pan American Health Organization, Management of dead bodies in disaster situations, Disaster manuals and guidelines series no. 5. Washington; 2004.

19. National Institute of Justice. Mass fatality incidents: a guide for human forensic identification, 2005. Avaliable from: http:// www.ojp.usdoj.gov/nij/pubs-sum/199758.htm.

20. Morgan O, Tidball-Binz M, Van Alpehn D, editors. Management of dead bodies after disasters: a field manual for first responders. Washington: Pan American Health Organization; 2006.

21. Prinz M, Carracedo A, Mayr WR, Morling N, Parsons TJ, Sajantila A, et al. DNA Commission of the International Society for Forensic Genetics (ISFG): recommendations regarding the role of forensic genetics for disaster victim identification (DVI). International Society for Forensic Genetics. Forensic Sci Int Genet. 2007;1(1):3-12. 
22. Lee J, Scott P, Carroll D, Eckhoff C, Harbison $\mathrm{S}$, lentile $\mathrm{V}$, et al. Recommendations for DNA laboratories supporting Disaster Victim Identification (DVI) Operations - Australian and New Zealand consensus on ISFG recommendations. Forensic Sci Int Genet. 2008;3(1):54-6.

23. Simas Filho F. A prova na investigação de paternidade - doutrina e jurisprudência. 10a ed. rev. atual. S.L.: Ed. Juruá; 2007.

Recebido em: 11/09/09

Aprovado em: 08/12/09 